
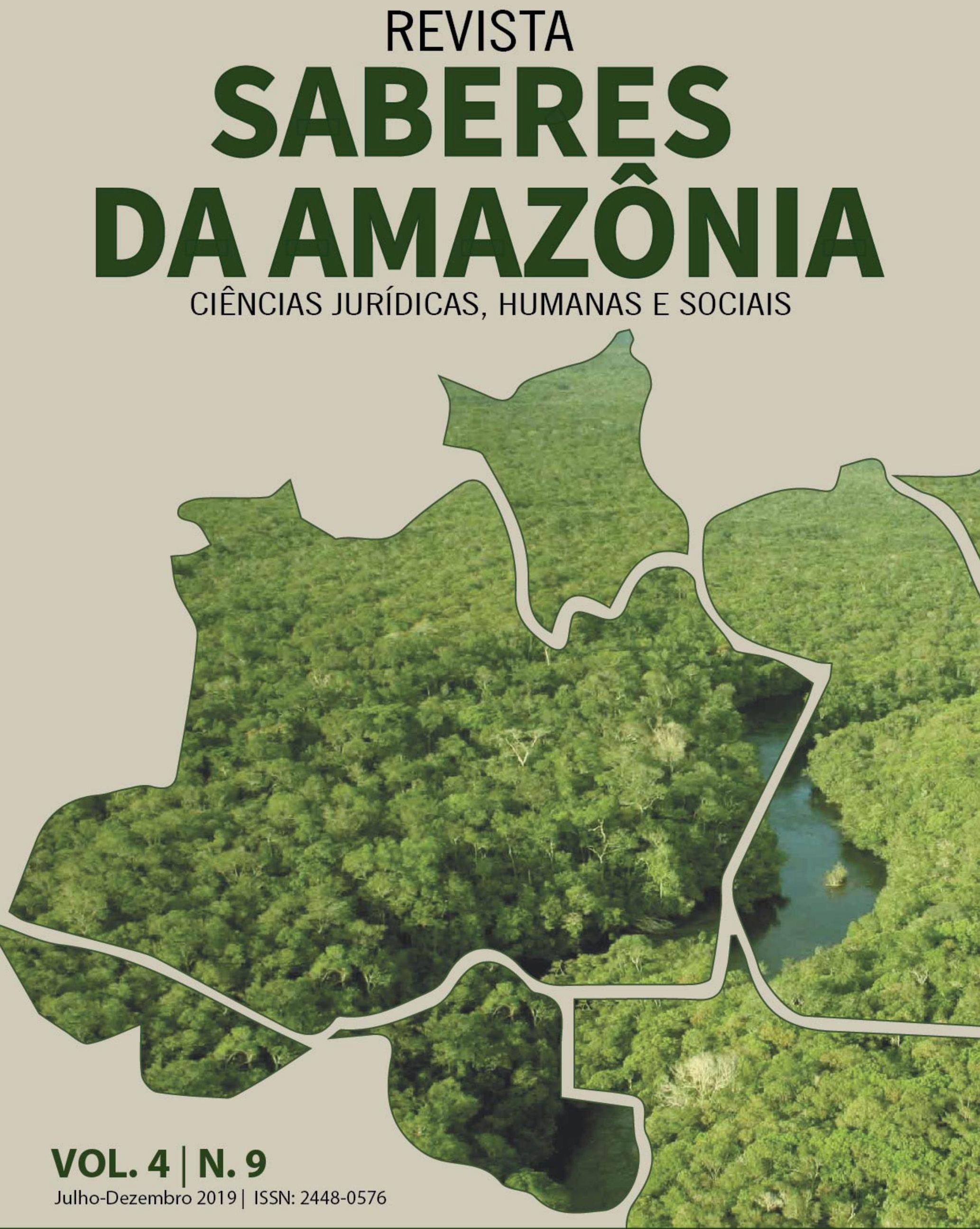


\title{
POLÍTICAS PÚBLICAS E PRESERVAÇÃO DA TRADIÇÃO AFRO- INDÍGENA DO COCO DE RODA EM CAETANO-CE
}

\author{
PUBLIC POLICIES AND PRESERVATION OF THE AFRO- \\ INDIGENOUS TRADITION OF COCO DE RODA IN CAETANO-CE
}

\author{
Samia Nagib Maluf ${ }^{1}$ \\ Alexandre Dos Santos Rocha²
}

\section{Resumo}

O presente estudo discute o legado ancestral da dança do Coco de Roda como uma expressão cultural que acessa a memória e a identidade local tanto dos brincantes, que estão na roda, quanto dos moradores, quando estes participam como expectadores. Estudar a prática brincante do Coco de Roda nos coquistas é colaborar com a manutenção de uma tradição que corrobora para um pertencimento étnico, capaz de produzir significados para a comunidade que é herdeira do passado que ressurge nas práticas cotidianas brincantes de Caetano que contribui para a formulação de políticas públicas de preservação e manutenção do patrimônio cultural local. Este também merece ressalvas em seu uso porque surge no contexto colonial que invisibiliza a cultura afroindígena. Para desvelar essa discussão foi preciso estabelecer um tipo de metodologia denominada de História Oral que tece uma relação entre sujeito e sua tradição cultural por meio de depoimentos que se constituem em narrativas carregadas de significados até para quem não pertence a tradição da comunidade. Por fim, diante dessa sociedade opressora e racista que nega as tradições populares de matriz afro-indígena que se constitui como uma prática de resistência e pertencimento dos brincantes e moradores ao legado ancestral da região.

Palavras-chave: Dança do Coco de Roda. Preservação do patrimônio cultural. Políticas Públicas.

1 Pós-Doutora Universidade do Minho, UMINHO, Portugal. Doutora em Economia Universidade Federal do Ceará, UFC. Mestre em Engenharia de Produção Universidade Federal de Santa Catarina, UFSC. Professora Associada, Vice-Diretora do Instituto de Ciências Sociais Aplicadas (ICSA). Redenção, CE - Brasil. E-mail: samia@unilab.edu.br

2 Mestre em Educação e Ensino. Faculdade de Filosofia Dom Aureliano Matos, FAFIDAM. Beberibe, CE, Brasil. E-mail: alesantos58@ hotmail.com. 


\section{Abstract}

The present study discusses the ancestral legacy of the Coco de Roda dance as a cultural expression that accesses the memory and local identity of both the players in the roda and the residents when they participate as spectators. To study the practice of Coco de Roda in the coquistas is to collaborate with the maintenance of a tradition that corroborates to an ethnic belonging, capable of producing meanings for the community that is heir of the past that reappears in the everyday practices of Caetano that contributes to the formulation of public policies for the preservation of local cultural heritage. To unveil this discussion, it was necessary to establish a type of methodology called Oral History that is capable of establishing a relation between subject and its cultural tradition through testimonies that are in narratives loaded with meanings for who is representative of this know-how of the locality. Finally, before this oppressive and racist society that annuls everything that does not have relation with the European world-system, the dance constitutes as a practice of resistance and belongs of the players and residents to the ancestral legacy of the region.

Keywords: Dance of the Coco de Roda. Preservation of cultural heritage. Public policy.

\section{Introdução}

O presente estudo foi realizado no município de Beberibe, no litoral leste do estado do Ceará à 85 km de Fortaleza. Possui uma população de 49.334, conforme o último Censo do IBGE/2010. Segundo a estimativa do mesmo órgão para 2018 é de mais 53 mil habitantes. Nesse contexto está inserida a comunidade de Caetano que fica à $12 \mathrm{~km}$ da sede do município de Beberibe. É uma localidade que sobrevive da pesca, da agricultura, do trabalho braçal feito por diárias, pequenos comércios varejistas e serviços de caseiros nas residências de veraneios que ficam às margens da Lagoa do Uruaú. Esse patrimônio natural banha uma parte das terras que deram origem ao povoado de Caetano no século XVIII.

O objetivo de pesquisar a dança do Coco de Roda baseia-se no fato de que a prática dessa dança se constitui como educativa por trazer ensinamentos aos brincantes enquanto brincam no centro da roda. Os saberes ancestrais nos passos dos coquistas, dos instrumentos, da poética das emboladas faz a dança formar uma identidade de pertencimento nos brincantes e afirma o legado afroindígena da comunidade que contribui para a formulação de políticas públicas 
de preservação da manifestação que é reconhecida como um patrimônio na comunidade como descreve os artigos 125; 216 e 225 da Constituição ${ }^{3}$. O termo patrimônio cultural é usado de maneira corriqueira pelos agentes públicos como ação de salvaguarda da herança cultural de grupos que se expressam pelas artes dramáticas.

Os coquistas expressam a cultura de resistência durante a prática brincante porque a tradição da dança afirma o legado ancestral dos moradores. Os mais velhos ao ver os jovens dançando o Coco, dizem que estão errando os passos e não percebem que a tradição para continuar existindo precisa ser reapropriada pelos novos sujeitos brincantes. Jucicléia Nascimento de Sousa e José Maria (Magal) são mestres do Coco que repassam seus conhecimentos aos jovens que desejam aprender a dança do Coco para dá continuidade à tradição na comunidade.

Por fim, é uma pesquisa engajada e comprometida com o entendimento das práticas culturais de resistência afro-indígena dos brincantes que compõem o Coco de Roda da comunidade. Preservar essa tradição é fundamental para a continuidade dos saberes desses sujeitos que reclamam a formulação de políticas públicas voltadas ao patrimônio imaterial dos coquistas. Por mais que o termo patrimônio mereça uma análise crítica em sua concepção epistemológica, o mesmo tem sido usado como ferramenta de luta dos grupos que resistem a perda das tradições.

\section{Desenvolvimento}

O estudo dos cocos sempre no plural conforme Mário de Andrade no livro: Os cocos. Resultado de uma pesquisa documental entre as décadas de 20 e 30 do século passado. Está inserido num contexto maior que abarca os estudos sobre aquilo que ficou conhecido como cultura popular como foi preservado pela primeira lei brasileira de preservação do patrimônio histórico e

3 BRASIL, Constituição da República Federativa do. Câmara dos Deputados, Centro de Documentação e Informação. $\quad$ Disponível em: <http://www.planalto.gov.br/ccivil_03/Constituicao/Constituicao.htm> Acesso em 02/10/2018. 
cultural, o Decreto-Lei $n^{0} 2^{4}$. Expressão bastante cara para os estudos culturais contemporâneos. O que se convencionou em chamar de cultura popular nada é mais do que uma oposição ao saber erudito, que transita neste. A fronteira entre as várias culturas do povo e da elite é vaga e por isso a atenção dos estudiosos do assunto deveria concentrar-se na interação e não na divisão entre as culturas. Divisão que pouco ou não contribui para seu entendimento 5 .

Desde a colonização europeia a partir de 1530, fala-se em preservar, registrar e incentivar a cultura dos menos favorecidos, prestes a desaparecer no torvelinho da modernidade nascente. Além de confundir uma suposta cultura do povo (dos pobres, dos analfabetos, dos camponeses, entre outros) com uma cultura popular (em oposição à cultura erudita), o discurso da preservação e do resgate nega as dinâmicas culturais que constituem todo o processo histórico de construção das sociabilidades humanas ${ }^{6}$.

A história do Brasil foi construída à custa de muita repressão da cultura popular. No Rio de Janeiro e em muitos outros lugares, no início do século XX, as pessoas eram presas e torturadas por simplesmente possuírem um pandeiro. Nos anos 40 na comunidade de Caetano, uma praticante da Umbanda foi perseguida por professar a sua fé. Por todo o século $X X$ a prática umbandista foi caso de polícia, principalmente nas comunidades de terreiros. Apesar de toda a repressão por parte das elites governantes, é impossível negar a imensa diversidade de manifestações culturais existentes no país. Essas manifestações culturais continuam em cena porque possuem sentido dentro dos grupos sociais aonde são praticadas.

Para Chartier ${ }^{7}$ a cultura popular é uma categoria erudita. Segundo este autor, o termo em questão oculta as diversas formas de vivenciar práticas culturais sob o manto do popular que hoje ganha destaque nas formulações de políticas públicas estatais sobre o manto do patrimônio que carrega fetiche e

4 BRASIL. Decreto-lei $n^{\circ} 25$, de 30 de novembro de 1937. Disponível em: <http://www.planalto.gov.br/ccivil_03/Decreto-Lei/Del0025.htm> Acesso em 02/10/2018. 5 BURKE, Peter. Cultura Popular na Idade Moderna. 2. São Paulo: Cia. das Letras, 1998. 6 BURKE, Peter. Cultura Popular na Idade Moderna. 2. São Paulo: Cia. das Letras, 1998. 7 CHARTIER, Roger. Cultura Popular. In: Revista Estudos Históricos. Rio de Janeiro: FGV, 1995. vol. 8, n. 16, p.179-192. 


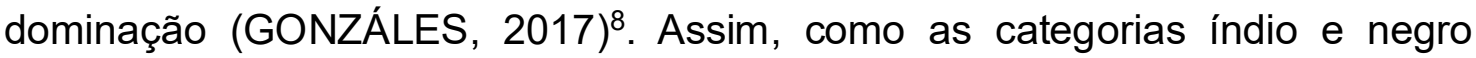
foram cunhadas por agentes do empreendimento colonial, os mesmos se apropriaram politicamente desse conceito genérico como forma de resistência a negação de sua diversidade. O termo cultura popular também possui esse sentido de generalizar e, muitas vezes, homogeneizar uma infinidade de práticas e costumes sociais num único conceito que serve como mecanismo para a criação de políticas públicas patrimoniais.

\subsection{Origem e estudo dos cocos}

Maria de Andrade define os cocos como expressão da cultura popular, oposição à cultura erudita ${ }^{9}$. Divisão social ingênua e perversa feitas pelos grupos pertencentes a esta ou aquela classe social que supostamente não compartilha dos costumes uns dos outros. A cultura em seu sentido amplo ultrapassa as barreiras impostas pelos agentes governamentais que formulam as políticas públicas que são responsáveis em proteger o que se convencionou a chamar de cultura do povo.

Segundo Burke ${ }^{10}$, é possível entender essa assimetria entre as culturas erudita e popular, a partir da forma como elas eram transmitidas: formalmente em liceus ${ }^{11}$ e universidades, tratava-se de uma tradição reservada a alguns poucos, fechada. A cultura popular, ao contrário, era transmitida informalmente, nas praças, nas tabernas, nos mercados e, em muitas das vezes, por sujeitos sem escolarização. Vale lembrar que, ruas, praças e mercados são espaços públicos, portanto, passível de serem frequentados por qualquer pessoa, desde as mais escolarizadas a analfabetas.

No decorrer dos séculos XVII e XVIII, as chamadas classes altas diminuem a sua participação nos costumes do povo ${ }^{12}$. Consideram-se as pessoas que não tiveram acesso a uma educação formal institucionalizada

8 GONZÁLES, Pablo Alonso. El antipatrimonio: fetichismo y dominación en Maragatería. Madrid: Consejo Superior de Investigaciones Científicas, 2017.

9 ANDRADE, Mário de. Os Cocos. 2. Belo Horizonte: Itatiaia, 2002.

10 BURKE, Peter. Cultura Popular na Idade Moderna. 2. São Paulo: Cia. das Letras, 1998.

$11 \mathrm{Na}$ Grécia Antiga, o Liceu (do grego antigo ^úkEıov, transl. Lykeion) era um gymnasion perto de Atenas. A palavra designa também a escola filosófica fundada por Aristóteles, em 335 a.C. (a escola peripatética).

12 BURKE, Peter. Cultura Popular na Idade Moderna. 2. São Paulo: Cia. das Letras, 1998. 
como pessoas sem conhecimento, sem cultura, ou possuidores de uma cultura inferior. O afastamento das elites em relação às festividades populares promove uma diferença entre as culturas de uns e outros. A cultura popular começa então a ocupar o lugar que lhe foi reservado por seu caráter participativo e comunitário.

A brincadeira do coco de roda não se limita aos seus brincantes, considerados, segundo a noção corrente de cultura popular que é fetichizada pelo capital, herdeiros de um saber-fazer passado de geração a geração através da oralidade. A cada dia aumenta o número de pessoas oriundas das classes sociais letradas, razoavelmente beneficiárias do sistema financeiro e educacional, que aderem aos costumes ditos populares devido a sua massificação por meio das políticas públicas estatais.

No Ceará, a articulação entre pessoas de diferentes condições socioeconômicas, liderados em sua maioria por jovens universitários, realizam o movimento de cultura popular tradicional, como dizem. Quando pretendem organizar um grupo dessa natureza, esses jovens visitam os lugares aonde moram os chamados mestres, que são nessa perspectiva os guardiões do saber tradicional, como os griot' $s^{13}$ na cultura africana.

A palavra cultura, ao longo do tempo, foi tomando corpo e significado em razão do processo de socialização dos sujeitos no espaço geográfico. No final do século XVIII e no princípio do seguinte, o termo germânico Kultur era utilizado para simbolizar todos os aspectos espirituais de uma comunidade, enquanto a palavra francesa Civilization referia-se principalmente às realizações materiais, de um povo por meio de seu espaço habitado ${ }^{14}$.

Tylor ${ }^{15}$, no vocábulo inglês Culture, que tomado em seu amplo sentido etnográfico é todo complexo que inclui conhecimentos, crenças, arte, moral, leis, costumes, valores, ou qualquer outra capacidade ou hábitos adquiridos

13 São os indivíduos que tinham o compromisso de preservar e transmitir histórias, fatos históricos e os conhecimentos e as canções de seu povo. Existem os griots músicos e os griots contadores de histórias.

14 LARAIA, Roque de Barros. Cultura: um conceito antropológico. 14 ed. Rio de Janeiro: Zahar, 2001.

15 TYLOR, Edward B. Primitive Culture: researches into the development of mythology, philosophy, religion language, art, and custom. Vol. I, London: John Murray, Albemarle Street, W., 1920. 
pelo homem como membro de uma sociedade'. Com esta definição Tylor abrangiam em uma só palavra todas as possibilidades de realização humana material e imaterial, além de marcar fortemente o caráter de aprendizado da cultura em oposição à ideia de aquisição inata, transmitida por mecanismos biológicos, hereditários.

Um século se passou desde a definição de Tylor $^{16}$, era de se esperar que existisse nova definição para cultura por conta do nascimento da ciência antropológica nas primeiras décadas do século $\mathrm{XX}$ a respeito do conceito. Tal expectativa seria coerente com o otimismo de Kroeber apud Laraia ${ }^{17}$ que, em 1950, escreveu que a maior realização da Antropologia na primeira metade do século XX foi à ampliação e a clarificação do conceito de cultura, por isso que a cultura é definida como um conceito antropológico.

É consenso entre os historiadores e pesquisadores que a dança do Coco de Roda se originou em Alagoas e, mais precisamente, na região de Palmares devido ao trabalho da quebra de coco dos quilombolas. Segundo Duarte $^{18}$, convém de pronto acentuar, (o Coco) não foi originariamente uma dança de praieiros, de jangadeiros, de canoeiros, de irritantes das praias, dos canais ou lagoas; veio dos mocambos palmarinos, em plena Zona da Mata, dali para as senzalas e os terreiros dos engenhos, espaço festivo para os negros.

Segundo Fonte Filho ${ }^{19}$,

Reza a tradição que os negros, à procura dos cocos, sentavam-se ao chão e, para quebrar a dura casca do fruto, colocavam-no sobre uma pedra e nele batiam com outra, até que o coco rachasse. Como eram muitos ao mesmo tempo, o barulho das pedras batendo nos cocos e as conversas sempre animadas do grupo provocavam uma barulheira enorme.

Para Cascudo ${ }^{20}$, a dança do coco originou-se do trabalho de quebrar coco, nos palmeirais alagoanos, e apesar de a dança em roda ser costume

16 TYLOR, Edward B. Primitive Culture: researches into the development of mythology, philosophy, religion language, art, and custom. Vol. I, London: John Murray, Albemarle Street, W., 1920.

17 LARAIA, Roque de Barros. Cultura: um conceito antropológico. 14 ed. Rio de Janeiro: Zahar, 2001

18 DUARTE, Abelardo. Folclore negro das Alagoas. Maceió: Departamento de Assuntos Culturais, 1974

19 FONTE FILHO, Carlos da. Espetáculos Populares de Pernambuco. Recife: Bagaço, 1999, p. 119. 
indígena, para ele é inegável o traço africano. No Dicionário do Folclore Brasileiro do autor, diz: mas o canto a tempo marcado pelo ruído dos instrumentos percutidos e pelas palmas dos circunstantes, o movimento marcado do corpo feito pelos dançarinos, executando seus passos, isolada e sucessivamente, no meio do círculo formado pelos demais, deixam transparente a contribuição africana. Ainda Fonte Filho ${ }^{21}$, "em meio à zoeira que se formava, sempre quem se levantasse e começasse a dançar, num vibrante sapateado, ao qual todos, alegremente, procuravam unir as batidas ritmadas nos cocos e alegres cantorias, transformando tudo numa animada festa".

De acordo com Duarte ${ }^{22}$, o folguedo tem sua origem no batuque angolaconguense africana: afirma que o coco alagoano, na sua forma primitiva, de coco solto, dançado pelos negros escravos, é coreograficamente uma forma particular do velho batuque angola-conguense. Ou pelo menos, com ele tem pontos de semelhança ou serviu de fonte de inspiração para o coco atual dançado e cantado nas praias do litoral cearense. Segundo SOUSA, José Maria (Magal). Entrevista concedida a Alexandre dos Santos Rocha. Caetano, Beberibe, 09 ago. 2018, "e lá (Uruaú) eles pulavam muito, tinha um cara chamado de Cajumba. Tinha um lito de cachaça encostado, cada uma rodada ali, outro entrava. Mais ou menos 40 anos que eu vi esse coco".

O coco alagoano original do círculo de dançadores - a roda de coco - do qual sai isoladamente o par (ou mais de um), que vai dar umbigadas no par escolhido e sapatear, sendo substituído por este, e assim, sucessivamente, se opera a renovação dos pares no meio da sala. O uso do ganzá é um instrumento de percursão tipicamente africano que são confeccionados pelos próprios brincantes. Duarte ${ }^{23}$ contesta os estudos que davam a este instrumento uma origem indígena, dizendo que: o instrumento indígena

20 CASCUDO, Luís da Câmara. Dicionário do folclore brasileiro. Rio de Janeiro: Ediouro, 2001. 21 FONTE FILHO, Carlos da. Espetáculos Populares de Pernambuco. Recife: Bagaço, 1999, p. 119.

22 DUARTE, Abelardo. Folclore negro das Alagoas. Maceió: Departamento de Assuntos Culturais, 1974.

23 DUARTE, Abelardo. Folclore negro das Alagoas. Maceió: Departamento de Assuntos Culturais, 1974. 
(caracaxá) citado por Barbosa é das tribos do Xapuri do Amazonas. Os indígenas do Nordeste usavam o maracá, brinquedo usado para acalentar as crianças recém-nascidas Segundo SOUSA, José Maria (Magal). Entrevista concedida a Alexandre dos Santos Rocha. Caetano, Beberibe, 09 ago. 2018, "o pessoal me viram na casa de farinha para eu entrar no coco, tinha muita vontade, dai entrei. Pulei, pulei... Aí com poucos dias a negada disse: rapaz tu num sabe bater o ganzá não? Eu disse: rapaz é só o que sei fazer agora. Levava na brincadira (risos)".

Tanto para Cascudo ${ }^{24}$, quanto Duarte ${ }^{25}$, ambos falam do coco como uma dança vigorosa, um jogo - quase uma luta. Duarte ${ }^{26}$ descreve o coco como uma dança primitiva e extenuante, que requer esforço físico dos dançadores, no jogo das pernas e dos pés, tanto que é dançado geralmente em pisos de cimento ou tijolo. No Cararri a origem do coco está ligada ao acabamento a fim de tapar buracos no piso de chão batido. No caso, o de Caetano é dançado pelos brincantes nos terreiros das casas ou nos vázios urbanos de chão batido na comunidade. O folclorista alagoano é incisivo, quando critica certo "amaneiramento" no modo dançado atualmente. SOUSA, José Maria (Magal). Entrevista concedida a Alexandre dos Santos Rocha. Caetano, Beberibe, 09 ago. 2018. "aí pegava o ganzá, fui, fui... Pegava umas emboladas muito legal e até hoje tô tirando essas emboladas".

Antonio Joaquim de Macedo Soares, no Dicionário Brasileiro da Língua Portuguêsa ${ }^{27}$, citando outros estudiosos, descreve que em Luanda e outros distintos de Angola, o batuque consistia também num círculo formado de dançadores indo para o meio um preto ou preta, depois de executar vários passos, vai dar uma umbigada a que chamam samba que vem de semba, na pessoa que escolhe, a qual vai para o meio do círculo, substituindo-o Segundo SOUSA, José Maria (Magal). Entrevista concedida a Alexandre dos Santos

24 CASCUDO, Luís da Câmara. Dicionário do folclore brasileiro. Rio de Janeiro: Ediouro, 2001. 25 DUARTE, Abelardo. Folclore negro das Alagoas. Maceió: Departamento de Assuntos Culturais, 1974.

26 DUARTE, Abelardo. Folclore negro das Alagoas. Maceió: Departamento de Assuntos Culturais, 1974.

27 SOARES, Antônio Joaquim de Macedo. Dicionário Brasileiro da Língua Portuguêsa. Ministério da Educação e Cultura, Instituto Nacional do Livro, 1954. 
Rocha. Caetano, Beberibe, 09 ago. 2018, "não é como antes (coco), mas tô tirando as emboladas do coco muita gente aqui quem tirava era Pedro Miguel, tirava. Embolador, finado Manezim, meu cunhado, era muito bom embolador. Tinha o Chico Edite, filho do Manezim, esse era que era bom na embolada".

O sapateado do coco, por sua variedade e pela recorrência ao plano baixo, nos remetem, em muitos aspectos, aos da capoeira. Têm nomes sugestivos: travessão, cavalo manco, trupé (tropel) repartido, sete-e-meio, dentre outros. Para Cascudo ${ }^{28}$ as fontes do sapateado brasileiro foram África e Portugal. Exímios sapateadores o são, em verdade, e sempre o foram portugueses e afro-negros.

No caso do coco, tanto a fonte podia ser a velha Península lbérica como o continente negro; mas, certamente, o foi à África. Trouxeram-no os afronegros, com as suas danças de estilos diversos e vamos encontrá-lo ainda, como acontece nas danças dramáticas, expressão de Mário de Andrade, especialmente no reisado e no guerreiro, cujos sapateados (tropéis) denotando a remota origem africana, evocam em nossos dias a presença do elemento negro. Duarte se refere, particularmente, aos reisados de congo, tão numerosos em Alagoas quanto no Cariri cearense, observando neles passos comuns aos cocos, como o trupé partido e o cavalo manco ${ }^{29}$. Em 2018, o Estado de Alagoas formulou ações planejadas que deram suporte para a construção de políticas públicas que tornaram o Coco de Roda patrimônio imaterial do povo alagoano.

\subsection{Os cocos no litoral: saberes-fazeres ancestrais}

No Ceará, o coco vem desde o século XVIII, difundindo-se tanto pelo interior, quanto pelo litoral. Foi se ressignificando de acordo com as caracteristicas socioculturais de cada região. Nesse estado, por força da forte presença indígena, sofreu modificações importantes para o folguedo existir nesses locais. Nos estudos dos Reisados de Congo, escrito em 1996, Duarte já

28 CASCUDO, Luís da Câmara. Dicionário do folclore brasileiro. Rio de Janeiro: Ediouro, 2001. 29 DUARTE, Abelardo. Folclore negro das Alagoas. Maceió: Departamento de Assuntos Culturais, 1974. 
discute os costumes dos índios do Nordeste. A participação da mulher é vedada em muitos dos nossos folguedos tradicionais. Os homens cantavam, dançavam e tocavam, exibindo-se para o público. Já às mulheres, reservava-se a função de receber os presentes dos admiradores e distribuir o alimento para os brincantes após a roda ${ }^{30}$.

Isso explica a ausência de mulheres nos cocos dos sertões e, principalmente, das praias cearenses. Na comunidade de Caetano a falta da presença de mulheres foi resolvida quando a umbigada passou a ser inserida na roda, antes formada só por homens. Executar esse movimento ficava bastante incomodo devido ao local e a inclinação do corpo. A cultura machista que imperou tão fortemente por todo o século $X X$ não permitia ao comportamento masculino.

Quando ainda havia a ausência das mulheres na roda de coco, houve a substituiu da umbigada pelo desafio guerreiro. O sapatear do coquista no centro da roda, chama outro para o meio da roda num desafio em duelo. Os dois trocam passos, como a imitar uma peleja, um deles sai vencedor, com o direito de permanecer no centro da roda e desafiar outro para um novo duelo. Quando passa a existir um vencedor, o coco vira jogo, peleja, o que acontece numa cantoria de viola ou num desafio de embolada.

O gingado do conquista, que vai do plano médio ao plano baixo, é encontrado no desempenho das balizas dos maracatus cearenses que trazem os passos da capoeira. Outra aproximação com a capoeira. De maneira semelhante à dos capoeiristas que vinham abrindo alas para os blocos carnavalescos de Pernambuco, fazendo derivar o frevo. Os passos das balizas são em ritmo mais pausado, quase em câmera lenta, feito caranguejos ou siris, para acompanhar a batida solene desta dança de negros, que precedia as coroações dos reis de Congo, coroados no Brasil, sob a proteção dos chamados santos pretos.

Os antigos brincantes do coco de Caetano ao ver os jovens na roda falam que eles não estão dançando certo. Isso se deve a ressignificação da

30 DUARTE, Abelardo. Folclore negro das Alagoas. Maceió: Departamento de Assuntos Culturais, 1974. 
própria brincadeira devido à inserção de novos sujeitos. Os antigos brincantes não entendem essa dinâmica da tradição que foi iniciada na comunidade por José Fernandes da Silva que a trouxe dos ritmos do fandango e da marujada que vivenciava nos navios que embarcavam e desembarcavam no Porto do Mucuripe em Fortaleza na década de 60.

Segundo SOUSA, José Maria (Magal). Entrevista concedida a Alexandre dos Santos Rocha. Caetano, Beberibe, 09 ago. 2018,

Fui pescador, gravei um disco também, né. Continuo com a dança do coco, porque faz muita parte de mim. Esse coco, eu conheci esse coco eu acho que eu tinha 12 anos. Quando eu assisti..., é esse padre Nonato, Nonato. Eles iam pra minha terra, Uruaú. Foi lá que eu vi pela primeira vez esses cocos. E lá, eles pulavam muito, tinha um cara chamado Cajumba, um lito de cachaça encostado, cada uma rodada ali, outro entrava. Mais ou menos uns 40 anos, que eu vi esse coco.

O depoimento descreve um período importante da dança na comunidade e de como os coquistas divulgam a brincadeira para outras localidades do município. A maneira que os brincantes apresentavam tanto nos paços como na poética do embolador, despertava um sentimento de pertencimento que motivava quem estava como espectador da roda a participar devido ao clima festivo que contribui com a quebra das normas sociais herdadas do patriarcalismo.

A Dança do Coco também chamada de "bambelô" ou "zamba" tem a origem na cultura afro-indígena, devido às trocas culturais e simbólicas entre os grupos étnicos (índios e negros) estabeleceram por conta da dominação europeia. Houve o que nós podemos chamar de fusão de elementos característicos de cada cultura agregado aos valores e costumes de cada região de nosso país, como, em Caetano que se dança o Coco de Roda por conta das adaptações que sofreu durante os processos históricos e sociais que modificaram e se transformaram para ganhar elementos próprios desse espaço geográfico.

Segundo SOUSA, Jucicléia Nascimento de. Entrevista concedida a Alexandre dos Santos Rocha. Caetano, Beberibe, 09 ago. 2018, "a dança tem origem na comunidade pela presença de muitos pescadores que praticavam esta atividade nas praias de Frecheiras (Praia das Fontes) e Diogo, que ao 
retornar da pescaria viam a pé por cima dos morros até chegarem a Caetano". Daí surge à dança e os passos por conta de os pescadores virem descalços na areia escaldante dos morros que ligam geograficamente estas comunidades.

Para SOUSA, José Maria (Magal). Entrevista concedida a Alexandre dos Santos Rocha. Caetano, Beberibe, 09 ago. 2018. Afirma que "a dança teve origem na localidade pelo meu cunhado Manoel Raimundo da Silva que aprendeu com seu pai José Fernandes da Silva que trouxe de Fortaleza". Essas duas versões para o surgimento do Coco de Roda na comunidade de Caetano na década de 60 , está relacionada ao povoamento afro-indígena de Caetano. Qual será a verdadeira "origem" na comunidade? Consideramos que a dança possui essas duas origens, sendo que se adaptou bem em Caetano devido às características geográfica e históricas marcadas pela atividade da pesca. Todos os brincantes do coco tradicional eram pescadores e usavam os morros como caminho para chegar à praia de Freicheiras ${ }^{31}$ onde suas jangadas estavam ancoradas.

$\mathrm{Na}$ comunidade de Caetano se dança o Coco de Roda em vez do Coco de Praia, característico na localidade de Iguape no município de Aquiraz, estudada pelo antropólogo Ninno Amorim que escreveu Em cima da hora: uma etnografia da brincadeira do coco no Iguape (CE). Essa diversidade de cocos é por conta das características naturais, históricas e socioculturais que definem o tipo de coco de cada região. As diferenças entre os dois estão nos passos, ritmo, percussão e sintonia. O Coco de Roda dança de pares, os dois dão um paço para frente e se vira para trás acompanhando o movimento da roda ao som do ganzá, o giro da mesma que se assemelha ao gira dos terreiros de Umbanda e Candomblé. O de Praia é de ritmo acelerado que lembra um sapateado pulado.

Os passos da dança, contudo, de maneira geral, apresenta uma forma básica: os participantes formam filas ou rodas onde executam o sapateado característico, respondem o coro, e batem palmas marcando o ritmo. Muito comum também é a presença do mestre "cantadô" ou "tirador" de coco. A festa

31 Fica a $7 \mathrm{~km}$ do centro do município. Comunidade de pescadores, marisqueiras, rendeiras, pequenos comércios varejistas, bodega e de uma rede de hotéis, pousadas, restaurantes e barracas de praia. 
sempre inicia quando ele "puxa" os cantos, que podem ser de improviso ou já conhecidos pelos demais.

\subsection{A roda de coco: dança e práticas afro-indígenas}

A roda de coco é um momento festivo que passa por constante ressignificação devido a inserção de novos sujeitos. As experiências e vivencias dos brincantes são incorporadas ao grupo por meio de práticas culturais que modifica a cultura dos brincantes no grupo que vem passando por mudanças devido a ressignificação das tradições. É necessário compreender que a cultura é dinâmica e reflete as interações do sujeito com o espaço.

Os brincantes que chegam à roda compreendem que a brincadeira do coco passa por transformações. Há um saudosismo pelos mais velhos quando fazem referência ao surgimento do Coco na comunidade, mas acabam deixando claro que "os tempos são outros". Essa expressão corrobora com os conflitos gerados pelos antigos brincantes que dizem que os "novos" não sabem o Coco como relata a coquista SOUSA, Jucicléia Nascimento de. Entrevista concedida a Alexandre dos Santos Rocha. Caetano, Beberibe, 09 ago. 2018. Ficou apenas nas falácias, os que ainda estão vivos não vão assistir as apresentações da roda do Coco dos jovens. Um ato que gera bastante discussão no grupo que é flexível tanto no número de pessoas quanto de participantes.

A flexibilidade na formação do grupo do coco está atrelada a vida dos jovens que estudam e trabalham nos mais diferentes locais do município. Cada um possui suas experiências entrelaçadas a luta diária pela sobrevivência e que encontra na roda do coco um momento festivo que os conduzem a uma prática educativa que gera afirmação identitária com a história local que perpassa a sua existência. Os cantos ritmados ao som do ganzá do tirador de coco Magal religam os brincantes a um passado ancestral afro-indígena na comunidade.

O estudo dos cocos está inserido num contexto maior que abarca os estudos sobre aquilo que ficou conhecido como cultura popular, oposição ao erudito, clássico. Contextualizar a entrada em cena desse personagem - o 
popular - e as implicações dessa estreia nas principais interpretações que orientaram as reflexões de importantes pesquisadores ao longo da história ${ }^{32}$.

A localidade está se reconhecendo como parte de si mesma e como detentora do saber popular. $\mathrm{Na}$ sociedade contemporânea, onde as desigualdades sociais se tornam latentes, ganha espaço as faces reivindicatória e propositiva de vários grupos minoritários ou subalternizados que são silenciados pela ideologia do branqueamento.

A partir da década de 1990, quando entram em cena os novos movimentos sociais, os quais expressam novas maneiras de luta e de resistência, as desigualdades enfrentadas pelos diversos grupos discriminados na sociedade brasileira são evidenciadas através de seus saberes-fazeres que recriam suas trajetórias de enfrentamento. Intensificam-se as discussões acerca da conjuntura do novo capitalismo, a partir do qual apenas uma minoria detentora dos bens de produção pode usufruir das oportunidades geradas pela globalização mundial que recai sobre a disputa de países que lideram a governança global. Para os demais, pobres e marginalizados, restam apenas os riscos e as incertezas.

O Coco de Roda se constitui como expressão cultural porque além de ensinar fora de quatro paredes estimula nos brincantes o pensar que forma sujeitos capazes de subverter a ordem posta através dos movimentos sociais que conduz a uma atividade cultural de resistência nos dizeres de Lúcia Helena de Brito $^{33}$. O discurso institucionalizado age nessa resistência por meio da desvalorização que é sustentada pelo discurso ideológico que nega a construção desse saber aos grupos marginalizados.

A construção de identidades dos moradores de Caetano busca-se através de suas práticas brincantes. Para SOUSA, José Maria (Magal). Entrevista concedida a Alexandre dos Santos Rocha. Caetano, Beberibe, 09 ago. 2018, diz: "fui pescador, gravei um disco também né. Continuo com a

32 SILVA, Djanilson Amorim da Silva. Os cocos no Ceará: dança, música e poesia oral em Balbino e Iguape. 2008.

33 BRITO, Lúcia Helena de. A poética da oralidade na cultura popular e sua dimensão educativa. In: FERNANDES, Liduína Maria Vieira; CHAVES, Sérgio Wellington Freire; LIMA, Denise Noronha. Diálogos temáticos: literatura contemporânea e sociedade. Fortaleza: HBM Shopping das Cópias, 2016. 
dança do coco, porque faz muita parte de mim". O sentimento de pertencimento reforça o caráter identitário no coquista como uma forma de resistência a desvalorização do legado afro-indígena na comunidade.

Busca-se uma aproximação com as teorizações que se aproximam do projeto epistemológico, político, étnico e social construído a partir de uma crítica à modernidade ocidental que é sólida, mas se desmancha no ar. O desenvolvimento prático de uma consciência linguística crítica ou uma prática de intervenção que possa contribuir para a transformação social, através da educação linguística de nossos alunos e do fortalecimento das práticas discursivas libertadoras em nossas comunidades, depende essencialmente de nossa atuação política ${ }^{34}$.

Nosso ser político se assenta na escolha do problema investigado que se encontra no campo dos estudos da construção de identidades que na sociedade contemporânea se torna líquida por meio dos contextos marcados pela colonialidade do saber e a subalternização de diversos grupos sociais pela perspectiva eurocêntrica dominante que surge de maneira ideológica no século $X X I$, em razão da crise estrutural do capital que se configura no plano do pensamento. Com isso, esperamos contribuir para a construção de conhecimentos que vão além dos fundamentalismos que asseveram a discriminação e legitimam o poder.

A ideia não é negar o conhecimento produzido na modernidade pela Europa, mas mostrar que os outros conhecimentos são tão válidos quanto aqueles hegemônicos, como dos brincantes do Coco de Roda, mesmo não conhecendo os códigos linguísticos do saber letrado, conseguem produzir saberes, que por meio da dança se transforma em práticas culturais de resistência. Esse saber na modernidade é invisibilizado pela cultura eurocêntrica nos espaços educacionais. Por isso, que a educação informal permite romper com esse discurso que ainda impera nas instituições sociais e nos currículos escolares.

34 ALENCAR, C. N. Linguagem e medo da morte: uma introdução à linguística integracionista. Fortaleza: EdUECE, 2009. 
Os brincantes do Coco de Roda dos anos 70 na comunidade iniciaram um movimento de empoderamento contra as práticas de negação dos saberes negros da cultura afro-indígena na localidade. Segundo SOUSA, José Maria (Magal). Entrevista concedida a Alexandre dos Santos Rocha. Caetano, Beberibe, 09 ago. 2018, "esse coco, eu conheci esse coco eu acho que eu tinha 12 anos. Quando eu assisti..., é esse padre Nonato, Nonato. O pai do Nonato, eles iam pra minha terra, Uruaú. Foi lá que eu vi pela primeira vez esses cocos".

Os brincantes que José Maria (Magal) conheceu a maioria deles eram pescadores e agricultores que desejavam aprender a escrever o nome no Movimento Brasileiro de Alfabetização - MOBRAL. A professora Jucicleide do Nascimento Silva (in memorian), entrevistada em 2008, disse-nos: "ensinava os brincantes as primeiras letras, usando os saberes da pesquisa e do coco. [...] nunca aprendi a dançar o coco, devido os passos serem difíceis. Ajudava o grupo na organização da alimentação nos dias de apresentação que raiava o $\mathrm{dia}^{35}$.

A coordenadora do Mobral em nível de Estado era a professora Lyrysse Porto de Araújo que se destacou no cenário cultural cearense pela militância a favor da cultural do Estado. Durante as visitas onde funcionavam as salas de aula nos interiores, passava a observar as práticas dos lugares e dos grupos que se alfabetizavam. Passou a contribuir com roupas para as várias apresentações que o grupo fez na localidade, TV Ceará (Canal 05) e na Coordenadoria de Desenvolvimento da Educação - CREDE 9 em Horizonte.

No final dos anos 30, a jovem Lyrysse Porto de Araújo iniciou a carreira no magistério ligado a Colônia dos Pescadores Z-1 que funcionava numa casa alugada em péssimo estado de conservação, com três salões e um quintal amplo que as crianças brincavam. Como professora dos filhos dos pescadores da Praia de Iracema, passou a ter mais contato com Jacaré que lhe pediu que

$35 \mathrm{ROCHA}$, Alexandre dos Santos. Vestígios arqueológicos (Século $\mathbf{X X}$ ): uma historiografia sobre uma provável origem da comunidade de Caetano-Beberibe. Monografia (Graduação em História) - Departamento de História, Centro de Humanidades. Beberibe: Universidade Estadual Vale do Acaraú, 2008. 
o ensinasse a ler e escrever para ir lutar pelos direitos dos pescadores no Rio de Janeiro à época presidente da República Getúlio Vargas ${ }^{36}$.

Diante da atual organização social, na qual as práticas neoliberais são hegemônicas e buscam manter um padrão global, há formas de resistências provenientes dos espaços sociais que o padrão eurocêntrico do poder convencionou chamar de periférico. A luta contra as imposições da dominação capitalista materializa-se nas lutas cotidianas dos moradores da comunidade de Caetano, que lutam pelo espaço que habita devido à grande especulação imobiliária na APA $^{37}$ da Lagoa do Uruaú. Os moradores do litoral sofrem os impactos advindos da crescente exploração sem controle dos recursos naturais, destinados as práticas turísticas que necessitam de formulação de políticas públicas para seu combate.

\section{Metodologia}

Para compreender o tema em estudo foi necessário eleger a metodologia de pesquisa da História Oral que permite um fiar e tecer entre sujeito e objeto de estudo. Para isso, foi preciso uma observação das práticas brincantes nos momentos de apresentação do grupo junto com a escuta sensível que estimula a fala-depoimento dos coquistas. Essa metodologia foi necessária para o estudo porque possibilitou um constante - fiar e tecer entre referencial teórico e procedimentos empíricos devido ao diálogo entre ambos (AMADO; FERREIRA, 2006).

A pesquisa possui um caráter de natureza aplicada que resulta mensurar um resultado posterior acerca das práticas brincantes dos coquistas. Para compreender essa mudança foi necessário elaborar um questionário semiestruturado digital com 10 perguntas discursivas que rementem uma abordagem qualitativa-exploratória que estão relacionadas as minhas observações em campo. A plataforma escolhida para criar o questionário

36 ABREU, Berenice. O Raid da Jangada São Pedro: Pescadores, Estado Novo e Lutas por Direitos. Rio de Janeiro, Universidade Federal Fluminense, 2007; DORÉ, Bernardo. A epopéia dos jangadeiros, nossos irmãos do mar. Fortaleza, s/ed. 1973.

37 Área de Proteção Ambiental. Patrimônio ambiental criada em 1999 pelo Decreto № 25.355, de 26 de janeiro. Situado no município de Beberibe-CE, compreendendo a Lagoa do Uruaú e suas margens e terrenos contíguos, com $26,7258 \mathrm{Km}^{2}$ e perímetro de $27,2514 \mathrm{Km}^{2}$. 
semiestruturado foi o Sistema Avalio 2.0, estudado na Disciplina de Tecnologias Aplicadas à Pesquisa.

As ferramentas do programa foram úteis para o trato das informações, apresentação dos dados e a facilidade de coletá-los por ser enviado por link pelo aplicativo de mensagens whatsApp para os brincantes, que se constituem por 16 jovens, sendo 08 que são mais assíduos por dispor de tempo. Dentre esses 08 , destinados a responder a pesquisa, foram escolhidos de início seus mestres, devido à dificuldade de encontrá-los para responder as perguntas. Foi enviado para dois brincantes jovens o questionário por whatsApp, mas não responderam. Diante dessa dificuldade, decidimos promover um encontro do grupo em novembro para a exibição do curta-metragem: Em busca das Africanidades $^{38}$ que mostra as expressões culturais da comunidade de Caetano, como a dança do Coco de Roda. Maneira que encontramos para estabelecer um diálogo e articulá-los.

\section{Apresentação e análise dos resultados}

Atualmente, tem sido recorrente o discurso da necessidade não só das pessoas serem alfabetizadas devido à imposição dos padrões eurocêntricos advindos da modernidade, fruto do projeto colonial português nas Américas que valorizava excessivamente o saber letrado que muitas vezes os grupos tradicionais não possuem porque sua lógica de reprodução está no saber-fazer, passado de geração a geração pela oralidade. Isso não quer dizer que os brincantes do Coco não possuíssem saber, este não está na escolarização, única forma válida para a sociedade ocidental. O conhecimento dos antigos brincantes estava firmado pelo que a Matriz Africana chama de tradição oral, pois se constitui a roda da vida (HAMPATÉ BÂ, 1982).

Compreendendo que os moradores das comunidades chamadas de tradicionais, por encontrarem-se na periferia do capitalismo, compõem um dos grupos que mais encontra dificuldades para ter acesso ao saber sistematizado, resta-nos questionar: a serviço de que/de quem estão os discursos e práticas,

38 Curta desenvolvimento pelo Projeto Beberibe Multicor - Arte e educação por uma infância sem racismo. 
de que no mundo contemporâneo todos devem se apropriar e dominar o conhecimento escolar que se tornou essencial para a garantia dos direitos socioculturais do povo.

A exigência da massificação do saber sistematizado entra em confronto com as práticas culturais dos brincantes do Coco por trazer em uma única vertente o processo histórico, no qual os moradores das comunidades tradicionais nos países subdesenvolvidos foram invisibilizados pelo eurocentrismo. Somente com o avanço do capitalismo e do processo de industrialização é que a educação passa a ser para "todos", por isso os brincantes inserem dentro de suas práticas a racionalização do sistema.

Com o avanço da economia e a necessidade da formação de mão de obra para o mercado e também para produção de matéria prima, a escola, através da oferta da educação formal, constitui-se como um espaço hegemônico para materialização e disseminação das ideologias da classe dominante, assumindo, muitas vezes, o papel principal na destruição do conhecimento tradicional dos brincantes do Coco, no rompimento das famílias e comunidades, e na desvalorização das tradições, deixando de lado o diálogo profundo entre as culturas, não considerando que todos têm tanto a aprender quanto a ensinar.

Mesmo os ideais da classe dominante se mantendo hegemônicos, vale salientar que eles não são únicos, pois se constituem apenas como a expressão do modo de vida e organização social que propagam o modo de ser de um bloco social em um determinado período da história. Concorrendo com os ideais de reprodução do sistema capitalista, encontramos nos espaços destinados as manifestações culturais como formas de resistências provenientes dos grupos subalternizados que ao lutar para defenderem seus interesses mostram que as ideologias organizam as massas humanas, formam o terreno sobre o qual os homens se movimentam, adquirem consciência de sua posição como militância (GRAMSCI, 1978). 


\section{Considerações finais}

É necessário ensaiar formas de transcender epistemologicamente o conhecimento eurocêntrico, o cânone ocidental, descolonizando, inclusive, a produção do ser, saber e poder que opera na concepção de patrimônio. Aqui, o saber produzido, aproveitável e necessário é muito maior que o ocidental, a verdade e a universalidade cedem lugar aos saberes que as comunidades tradicionais possuem e que aos poucos as políticas públicas tentam garantir a efetivação da preservação desse patrimônio. Segundo Michelon; Machado e Gonzáles (2012, p. 43) “a efetiva aplicação de políticas públicas do patrimônio visa contribuir com a preservação dos vestígios da história do Brasil, assim como garante a reflexão sobre a afirmação de nossa identidade".

Isso implica, necessariamente, no diálogo entre culturas, no aproveitamento dos diversos saberes, ampliando os conhecimentos aceitos e sistematizados pela humanidade por meio das práticas culturais presente nos elementos afro-indígenas do Coco de Roda de Caetano. Expressão cultural que se ressignifica devido a inserção de outros sujeitos brincantes que dão continuidade a preservação da tradição.

As gerações vão deixando cada uma ao seu modo suas impressões e modos de dizer e fazer. Para que a tradição continue é necessário haver mudanças e adaptações porque o espaço-tempo se modifica em razão dos sujeitos que nele habita. Isso gera sentimento de resistência nos brincantes e no sistema opressor colonial que ainda não foi superado mesmo com a Proclamação da República.

O Coco de Roda é uma expressão cultural que acessa um passado ancestral na comunidade de Caetano e colabora com os processos identitários dos brincantes e moradores devido a dança trazer os elementos do canto, dos passos, da roda, da vestimenta, dos instrumentos de percussão e da culinária, patrimônio afro-indígena que afirma a memória local. A preservação desse legado passa também pelas políticas públicas que institui ordenamentos jurídicos que em muitos casos não têm eficácia prática devido a mistura do público com o privado no sistema político brasileiro. 
A comunidade de Caetano tem a dança do Coco de Roda como uma prática de religação ao passado-presente dos ancestrais que chegaram a região e disseminaram a cultura de resistência por meio de seus saberesfazeres. Diante disso, a sociedade opressora e racista em que vivemos anula todas as manifestações que não fizerem relação com o eurocentrismo por identificá-las como não civilizadas, incultas e atrasadas.

\section{Referências}

AMADO, Janaina; FERREIRA, Marieta de Morais (Orgs.). Usos e abusos da História Oral. 8 ed. Rio de Janeiro: Editora FGV, 2006.

GRAMSCI, Antônio. Concepção Dialética da História. Civilização Brasileira, Rio de Janeiro, 1978.

HAMPATÉ BÂ, A. A tradição viva. In: KIZERBO. História oral da África: metodologia e pré-história. Vol. 1, São Paulo: Ática/UNESCO, 1982.

LUKÁCS, György. Per una Ontologia dell'Essere Sociale. V. 2, Roma: Riuniti, 1981.

MICHELON, Francisca Ferreira; MACHADO, Cláudio de Sá Júnior; GONZÁlEZ, Ana María Sosa (orgs.). Políticas públicas e patrimônio cultural: ensaios, trajetórias e contextos. Pelotas: Universidade Federal de Pelotas, 2012.

ROCHA, Alexandre dos Santos. Vestígios arqueológicos (Século $\mathbf{X X}$ ): uma historiografia sobre uma provável origem da comunidade de Caetano-Beberibe. Monografia (Graduação em História) - Departamento de História, Centro de Humanidades. Beberibe: Universidade Estadual Vale do Acaraú, 2008.

SOARES, Antônio Joaquim de Macedo. Dicionário Brasileiro da Língua Portuguêsa. Ministério da Educação e Cultura, Instituto Nacional do Livro, 1954. 